\title{
REFORMA DEL SISTEMA ECONÓMICO Y LA TESIS DE LAS TRES ECONOMÍAS
}

\section{REFORM OF ECONOMIC SYSTEM AND THE THESIS OF THE THREE ECONOMIES}

\author{
Manuel Figueroa \\ Exfuncionario de la CEPAL (Argentina) \\ mfk@fibertel.com.ar
}

Recibido: abril, 2014.

Versión final aceptada: junio, 2014.

PALABRAS CLAVE: Reforma sistema económico, Tesis de las Tres Economías, economía social-comunitaria, mercados sociales de trabajo, creación de empleos productivos.

KEYWORDS: Economic system reform, Thesis Three Economies, community social economy, social labor markets, creating productive jobs.

\section{RESUMEN}

La Tesis de las Tres Economías sustenta que para avanzar en la gradual resolución de los problemas de desempleo y pobreza, los países tendrán que consensuar nuevas ideas de políticas públicas para complementar los medulares aportes realizados, en sus respectivos tiempos históricos, por las escuelas de pensamiento surgidas en torno a las contrastantes ideas de Adam Smith, Carlos Marx, John M. Keynes y Raúl Prebisch. La Tesis propone, específicamente, institucionalizar reformas en el sistema económico para asegurar el buen funcionamiento simultáneo y convergente de un capitalismo competitivo de libre mercado, una eficaz economía pública con normas de seguridad jurídica y una nueva economía social-comunitaria que activando el funcionamiento de "mercados sociales de trabajo productivo" posibilite crear riquezas utilizando las energías de jóvenes y adultos desempleados.

\section{ABSTRACT}

The thesis of the Three Economies supports that progress in the gradual resolution of the problems of unemployment and poverty, countries will have to agree on public policy ideas to complement the core contributions made in their respective historical times, schools of thought emerged around the contrasting ideas of Adam Smith, Karl Marx, John M. Keynes and Raul Prebisch. The thesis proposes specifically institutionalize reforms in the economic system to ensure good convergent and concurrent operation of a competitive free market capitalism, an effective public

ISSN:0212-8594 ISSN-e: 2340-2776. № DOI: http://dx.doi.org/10.12795/rea.2014.i31.05 
economy standards of legal certainty and a new social-communal economy turning operation "social productive labor markets "enables creating wealth using the energies of young people and unemployed adults.

ISSN:0212-8594 ISSN-e: 2340-2776. № DOI: http://dx.doi.org/10.12795/rea.2014.i31.05 REA 31 (2014): 98-126

http://www.publius.us.es/estudios_andaluces 


\section{INTRODUCCIÓN.}

La Tesis de las Tres Economías postula que para la gradual resolución de los problemas de desempleo, pobreza e indigencia que degradan a sectores importantes de la población en diversas regiones del mundo, será esencial incorporar en la lucha por el progreso y la equidad, la acción del estado y del mercado motorizado por los empresarios. Los sectores sociales degradados o descartados hacia los bordes de la sociedad por las prácticas de un capitalismo despiadado deberían constituirse en un tercer actor social fundamental y participar, activamente, para reconstruir las sendas de la gobernabilidad, progreso y bienestar de todos los seres humanos. Para concretar esta utopía será imprescindible instituir una nueva forma de organizar la economía y de administrar el territorio para que las comunidades rurales y urbanas de bajos ingresos, las pequeñas y medianas empresas junto a los desempleados y excluidos del sistema acrecienten su participación en la riqueza nacional aportando sus energías mediante formas diversas de trabajo productivo. Esta determinación tendrá que institucionalizarse mediante leyes que reglamenten su necesaria aplicación.

El funcionamiento armónico de tres modalidades de funcionamiento económico será condición esencial para avanzar hacia el desarrollo nacional por los caminos de una democracia participativa que impulse el funcionamiento de formas diversas de organización económica: Economía privada de libre mercado con seguridad jurídica y normas regulatorias administradas por el Estado; Economía Pública bajo control de las instituciones de la República y, finalmente, una Economía Social-Comunitaria sustentada en la activa participación de una pluralidad de actores sociales: entidades cooperativas o comunitarias, pequeñas y mediadas empresas privadas, Organismos Públicos Regionales, Entidades Sociales Locales, con financiamiento y supervisión general del Estado Nacional. A partir de esta nueva configuración, el arte del buen gobierno consistirá en compatibilizar el espíritu de libre empresa y la vigencia del mercado como escenarios apropiados para la creación de riqueza, con las acciones permanentes de un nuevo Estado de Responsabilidad Social y la participación de la sociedad para la resolución de sus principales problemas productivos y sociales.

La Tesis de las Tres Economías, fundada en una visión realista del mundo contemporáneo, lejos de postular la desaparición del capital y de la propiedad privada como núcleo de organización social sustenta la necesidad de su ampliacióndentro de precisas normas legales de regulación económica. Con la activa participación del Estado, de las comunidades y de las empresas privadas será posible implementar Políticas Públicas que impulsen la acumulación de capitales esenciales para el progreso

ISSN:0212-8594 ISSN-e: 2340-2776. № DOI: http://dx.doi.org/10.12795/rea.2014.i31.05 REA 31 (2014): 98-126

http://www.publius.us.es/estudios_andaluces 
económico, el pleno empleo de la fuerza de trabajo con remuneraciones de vida digna y una distribución funcional del ingreso nacional más equitativa que armonice los requerimientos endógenos del capitalismo con valores supremos que sustenten el progreso de los países y la dignidad de las personas.

La necesidad de reformar los sistemas económicos para posibilitar el funcionamiento sincrónico de tres formas convergentes y complementarias de Economía no es una necesidad del presente tan solo para economías capitalistas de occidente, desarrolladas o subdesarrolladas. La experiencia de China pone en evidencia no solo su actualidad sino, básicamente, el éxito consumado por su Gobierno al reorganizar la economía del país de forma a posibilitar el funcionamiento armónico y simultáneo de tres formas de economías complementarias y convergentes.

Hacia fines de la década de los 70, sus principales líderes comprendieron que la cooperación internacional mediante la apertura de la economía y el ingreso de empresas y capitales privados provenientes de todos los rincones del mundo sería el instrumento más apropiado para materializar aquellos propósitos. Más aún, comprendieron que la dinámica de la cooperación con las megaempresas privadas internacionales se situaba más allá del carácter capitalista o socialista del sistema social dominante en el propio país.

A comienzos del siglo XXI, China volvió a demostrar su audacia creativa ingresando, después de años de negociaciones, a la Organización Mundial del Comercio sincronizando el comportamiento de sus políticas internas con los patrones vigentes en la escena del comercio internacional en materias relativas a seguridad jurídica, liberación de mercados, normas de financiamiento y apertura de las cuentas de capital para facilitar el ingreso y la salida de divisas.

Documentos oficiales (Brahm, L. J., 2002) refieren que en los primeros años tras del ingreso a la OMC, China habría aprobado más de 340.000 proyectos extranjeros de inversión con más de 307.851 billones de dólares de capital extranjero. Por las normas de regulación establecidas respecto al capital extranjero, China pasó a recibir capitales y tecnologías de todos los países del mundo interesados en realizar operaciones mercantiles. Las inversiones en el país provienen de más de 180 países y entre las 500 empresas multinacionales más grandes del mundo, 400 han invertido y trabajan en China. Ya se abrieron a la cooperación las áreas del comercio de mercancías y servicios, comercio exterior, finanzas, seguros, seguridad, telecomunicaciones, turismo, y agencias de servicios. Sin embargo, tras 30 años de experiencia en las Políticas de Apertura, y no obstante la velocidad de las transformaciones ya experimentadas, aún

ISSN:0212-8594 ISSN-e: 2340-2776. № DOI: http://dx.doi.org/10.12795/rea.2014.i31.05 
se reconoce sensibles atrasos en la gestión de las Empresas Públicas y en las instituciones descentralizadas del Estado.

Por la escala de las transformaciones referidas, China, en la actualidad, configura un gran escenario social dentro del cual funcionan una amplia diversidad de formas económicas. Sin embargo, focalizando tan solo aquellas más representativas, destacan con sentido complementario y convergente, tres regímenes económicos simultáneos: la Economía Publica, con un amplio abanico de actividades que permanecen bajo dominio y administración del Estado; la Economía Privada movilizada por empresas nacionales y extranjeras, y la Economía Tradicional de las aldeas campesinas donde predominan todavía rasgos atávicos de una Economía Social-Comunitaria estructurada sobre una pluralidad de sistemas de propiedad de la tierra de carácter cooperativo, privado o comunitario.

Esta forma tradicional de economía, donde residen todavía cerca de 700 millones de personas, fue reestructurada y fomentada por el Gobierno después que se desactivaron las frustrantes experiencias de colectivización en el uso de la tierra dominantes en las décadas de los 50 y 60 . En la actualidad, las regiones rurales, dotadas de mayor infraestructura de transporte, educación y servicios públicos, disponen de mayores grados de libertad de comercialización y financiamiento. Su producción se destina al autoconsumo, a la transformación agroindustrial y al intercambio comercial local e interregional.

Por razones de consistencia en materia de ordenamiento territorial y desarrollo urbano-rural, los procesos migratorios desde las zonas rurales hacia las ciudades permanecen bajo estricto control de las autoridades de gobierno a fin de regular su afluencia a las ciudades. Las variables fundamentales que determinan la dinámica de las migraciones se relacionan con la intensidad de crecimiento de las economías urbanas y particularmente, por la disponibilidad de empleos, de viviendas, de servicios sociales, de transportes, de preservación ambiental.

\section{CARACTERIZACIÓN DE CADA TIPO DE ECONOMÍA.}

\section{- Economía Pública.}

Todo gobierno decidido a servir los intereses de la Nación y atender los requerimientos de la población podrá multiplicar su capacidad operativa mediante administración profesional. Sus grandes objetivos y responsabilidades serán los de formular y supervisar el conjunto de Políticas Públicas haciendo cumplir el marco jurídico establecido por la Constitución Nacional; velar por la seguridad y progreso de la Nación

ISSN:0212-8594 ISSN-e: 2340-2776. № DOI: http://dx.doi.org/10.12795/rea.2014.i31.05

REA 31 (2014): 98-126

http://www.publius.us.es/estudios_andaluces 
y el bienestar general de la población; asumir, en carácter de excepción, responsabilidades empresarias en la producción de bienes y servicios de alta prioridad nacional conforme determinación expresa del HCN, administrar el Presupuesto Nacional y racionalizar el gasto público para impulsar la gradual expansión de la economía aliviando el peso de la carga fiscal sobre las empresas privadas.

Con la creación de un parque nacional de grandes empresas dentro de los cuales el Estado pueda participar junto a empresas de origen nacional o internacional, los Gobiernos podrán recuperar gradualmente roles protagónicos, intensificar la racional explotación de sus recursos naturales, transformar el amplio patrimonio físico de sus territorios en capital financiero, volver a constituirse en sujeto de crédito internacional y expandir la propia generación de divisas para potenciar la diversificación productiva y honrar sus compromisos de endeudamiento sin depender, exclusivamente, del financiamiento externo o de los dólares generados por el sector privado comercial. Tales propósitos permitirán ganar autonomía de decisión en materia económica, estimular el desarrollo tecno-científico y reindustrializar el país, ejercer soberanía sobre su patrimonio físico y ampliar el empleo y la recaudación tributaria sin presionar en demasía al sector privado empresarial. La reorganización de la Economía Pública permitirá a los Gobiernos:

a) Racionalizar el gasto público y reducir la evasión tributaria

b) Reducir la presión fiscal sobre las empresas privadas

c) Asegurar la generación de bienes públicos esenciales

d) asegurar la disponibilidad de recursos financieros para destinarlos a la creación de empleos en mercados sociales de trabajo productivo garantizando un ingreso social de vida digna para todas las familias en situación de pobreza e indigencia

e) Asegurar la administración de servicios sociales esenciales de educación, salud, previsión social y saneamiento básico a toda la población y controlar la preservación ambiental bajo marcos legales de ordenamiento territorial.

f) Impulsar la radicación de mega-proyectos de inversión con capitales de origen interno o externo concediendo garantías de seguridad jurídica, estabilidad y libertad de mercados, de producción y apertura plena de la cuenta de capitales para administrar el destino de los excedentes. Podrá tratarse de grandes proyectos de energía hidroeléctrica, gas y petróleo, transporte fluvial, producción de máquinas y bienes de capital para las industrias naviera, ferroviaria, aeronáutica, flota mercante, explotación de yacimientos minerales,

ISSN:0212-8594 ISSN-e: 2340-2776. № DOI: http://dx.doi.org/10.12795/rea.2014.i31.05 
distritos de irrigación, canalización e intercomunicación de cuencas hidrográficas y otros emprendimientos de gran escala.

g) Ampliar el capital tecnocientífico del país impulsando la participación de Universidades y Empresas Privadas especializadas en programas de investigación,

h) Valorizar el territorio expandiendo los equipamientos productivos de infraestructura física y reformar el régimen de propiedad de la tierra y emprender mega proyectos de transferencias de población entre regiones del país facilitando la radicación de nuevos asentamientos productivos de carácter rural/urbanos.

i) Desplegar esfuerzos para potenciar los valores de la cultura y la identidad nacional.

j) Crear empresas del estado que posibiliten implementar mega proyectos de inversión en los campos de la alta tecnología, producción de bienes de capital; transporte, energía y telecomunicaciones habilitando la participación del capital nacional e internacional.

k) Poner en funcionamiento una Agencia Mixta de Comercio Exterior para potenciar sus alcances a escala internacional y ampliar la competencia con las grandes empresas multinacionales que actúan en el país.

\section{-Economía Privada de libre mercado.}

Reconociendo el principio de subsidiaridad en el desempeño de sus funciones, competerá al Estado y Gobierno adoptar las políticas apropiadas de Regulación y Control para que las empresas y organizaciones empresarias, con capitales de origen nacional y/o extranjero, puedan maximizar en el país los frutos de su trabajo y expandir, hasta donde les sea rentable y eficiente, sus niveles de inversión y producción para consolidar la vigencia del mercado, la sana competencia y el propio régimen de empresa privada. Por las manos de la economía privada el Estado aspira a multiplicar aceleradamente sus relaciones con la economía internacional ampliando el comercio exterior, acumulando divisas, incorporando nuevas inversiones productivas, accediendo al mundo de las tecnologías de última generación y potenciando el relacionamiento internacional del país para multiplicar la realización de negocios.

Bajo la tesis que se difunde en este trabajo, la empresa privada estará presente dentro de todos los espacios y manifestaciones cubiertos por las Tres Economías. Sin embargo, sus funciones serán diferenciadas y tan solo podrá imponer la fría lógica de

ISSN:0212-8594 ISSN-e: 2340-2776. № DOI: http://dx.doi.org/10.12795/rea.2014.i31.05 
su funcionamiento asumiendo roles hegemónicos en el espacio específico donde predominen las relaciones sociales del capitalismo pleno. En los espacios bajo normativas de la Economía Pública o de la Economía Social-Comunitaria, los mercados y la empresa privada seguirán siendo estimulados por el Gobierno para desempeñar roles dinámicos aunque subordinados a las respectivas lógicas de funcionamiento impuestas por el Estado y las comunidades.

Se reconoce que la lógica intrínseca al sistema capitalista determina la vocación natural del sector privado empresarial que siempre fue, es y será la de expandir sus negocios y maximizar sus excedentes. Si en la búsqueda de aquellos objetivos el sector privado cumple los marcos de regulación instituidos por las Políticas Públicas en materia de legislación social, laboral, provisional, ambiental y tributaria al Gobierno solo le competerá apoyar su gradual consolidación entendiendo con extrema claridad conceptual que su objetivo principal, naturalmente, es ganar más dinero.

En efecto, no hace a la esencia del capitalismo ni es de su directa incumbencia el generar el mayor número posible de puestos de trabajo ni garantizar el bienestar de la sociedad. Tales responsabilidades pertenecen, básicamente, al Estado y a la propia sociedad, independientemente del régimen político y del sistema social dominante en un país. Bajo tales consensos, la Empresa Privada, independientemente de su origen nacional o extranjero y de sus propias formas y dimensiones, gozará de todos los derechos y libertades consagradas por la Constitución Nacional y leyes especiales sancionadas por el HCN para ejercer la plenitud de sus actividades. Tales consensos, expresan con mayor amplitud los roles de la Empresa Privada en los procesos de desarrollo nacional, independientemente de la naturaleza del sistema político imperante en un determinado país.

\section{-Economía Social-Comunitaria.}

Reconociendo el imperio de aquella concepción, se asume que la Economía SocialComunitaria se inscribe como una alternativa organizacional posible para encaminar soluciones permanentes a problemas económicos y sociales que hasta el presente permanecen sin apropiada resolución. La densidad y trascendencia del tema nos obligó a recurrir a un autor que hizo escuela tratando el tema de la Justicia social. En su libro "El sacrificio y la envidia," Jean-Pierre Dupuy (1998) analiza las concepciones de John Rawls sobre la Justicia y dice:

"Es al mercado competitivo que confiamos el cuidado de asegurar que la afectación de los recursos sea eficaz. Pero es necesario que el mercado siga siendo realmente

ISSN:0212-8594 ISSN-e: 2340-2776. № DOI: http://dx.doi.org/10.12795/rea.2014.i31.05 
competitivo, lo que requiere la intervención legisladora (antimonopolio) del Estado. Ahora bien, la eficacia es una condición necesaria de la justicia aunque no suficiente. Así el mercado remunera el esfuerzo, el trabajo, la competencia, la responsabilidad, el riesgo y la suerte, pero ignora las necesidades. Es por ello que el Estado debe redistribuir las rentas primarias, por medio de impuestos y transferencias, con el fin de satisfacer el principio de diferencia, pero también y prioritariamente, los principios de igualdad de derechos, libertades y oportunidades. De ahí que sea necesario.....un sistema de transferencias a favor de los más desgraciados, asegurándoles un mínimo social lo más elevado posible (maximín) y una fiscalidad justamente repartida para financiar estas transferencias."

La Economía social-comunitaria se inscribe como una posibilidad política en contextos donde ni la economía pública ni la economía de mercado lograron resolver las extremas carencias sociales. Bajo las nuevas reglas que podrán regular este tipo de economía, los trabajadores desempleados o con ingresos insuficientes, percibirán, como mínimo, un ingreso social de vida digna y todas las familias tendrán los mismos derechos y obligaciones para insertarse en la legislación socio-laboral y en los programas públicos de educación, salud y previsión social.

Como contrapartida, aquellos miembros de familia en edad activa y aptos para el trabajo físico que hasta el presente vegetan en el terreno del desempleo o son beneficiarios de programas asistenciales promovidos por el gobierno, tendrán la doble responsabilidad de incorporarse a los proyectos de trabajo productivo diseñados para cada circunscripción y participar, junto a todos sus familiares en los programas de educación, capacitación y salud.

Vale mencionar que la conceptualización de Economía Social Comunitaria utilizada en este trabajo difiere sustancialmente de aquella vigente en países desarrollados. Desde 1948 las Naciones Unidas aprovechan la experiencia de la sociedad civil a través de la Conferencia de Organizaciones no Gubernamentales donde fundaciones y asociaciones del mundo reciben estatus consultivo, o sea, el derecho a formular propuestas a los estados miembros en una amplia variedad de temas. Solo en los EEUU, hacia el 2010, se estimaba en 1.280 .739 las instituciones filantrópicas existentes. En todos los países del mundo se registra la participación de estas organizaciones movilizadas por propósitos de ayuda y solidaridad. En su conjunto integran el Tercer Sector, según la conceptualización utilizada por Jeremy Rifkin (2000) en su reconocida obra "El fin del Trabajo".

ISSN:0212-8594 ISSN-e: 2340-2776. № DOI: http://dx.doi.org/10.12795/rea.2014.i31.05 
A diferencia de la concepción utilizada por Rifkin para definir el Tercer Sector, nuestra concepción de Economía Social-Comunitaria pertenece a otro vector axiológico dentro del cual la creación de un tercer tipo de economía social-comunitaria no resulta de impulsos originados al exterior de las zonas de pobreza; no expresa tampoco actos generosos de conciencia ni de actitudes compasivas de origen religioso. No se organiza para realizar actividades sin fines de lucro. Finalmente, no es producto de la voluntad de instituciones caritativas o filantrópicas radicadas en el exterior, particularmente en países ricos desarrollados que aportan expresivos recursos financieros para realizar proyectos de beneficio social.

La Economía Social-Comunitaria, aunque naturalmente podrá beneficiarse de todo gesto solidario impulsado desde instituciones filantrópicas de origen nacional o internacional, debería organizarse, como imperativo de la propia sociedad, para avanzar hacia su propio progreso y equidad mediante la puesta en marcha de nuevas actividades laborales utilizando la fuerza de trabajo desempleada. Algunas actividades tendrán un propósito eminentemente productivo, mercantil y comercial y serán organizadas para generar riqueza material y ganar dinero mediante actividades para mercado interno o externo; otras, las de carácter social, cultural o ambiental, podrán establecerse para proveer servicios en beneficio directo de las poblaciones locales En cuanto el primer tipo de actividades determina las remuneraciones al trabajo y sus niveles de ganancia en función de los datos del mercado, el trabajo excedente destinado a realizar las actividades de orden social y de preservación ambiental, aunque sin cotización en los mercados privados, tendrá que ser retribuido, reconocido y valorado en términos monetarios por el Gobierno a través de los Entes de Desarrollo Regional abriendo amplio espacio a la vigencia plena de precios políticos que responderán a valoraciones y determinaciones de la propia sociedad.

En tales situaciones, se reconoce y asigna valor económico a la creación y disponibilidad de servicios sociales esenciales como el cuidado de niños y ancianos bien como al desarrollo de actividades culturales, desarrollo de nuevos conocimientos o a la preservación ambiental, la reforestación, la arborización de espacios urbanos, la protección de cuencas, la limpieza de canales, la construcción de obras de saneamiento, la preservación de edificios públicos como escuelas, hospitales, la construcción de caminos vecinales, puentes o pequeños sistemas de irrigación, etc.

Tras el reconocimiento de valor por los bienes sociales, culturales y ambientales, la propia sociedad asume la decisión de asignar valor al trabajo productivo realizado en mercados sociales estableciendo, como norma general, que su nivel de remuneración

ISSN:0212-8594 ISSN-e: 2340-2776. № DOI: http://dx.doi.org/10.12795/rea.2014.i31.05 
tendrá que ser aquel que posibilite vida digna a la familia del trabajador más el libre acceso a los servicios sociales esenciales bajo responsabilidad del Estado. Naturalmente, los niveles de remuneraciones en los mercados sociales de trabajo productivo podrán variar de región en región conforme sean los costos diferenciados de la canasta de bienes esenciales pero dentro de cada región, el salario mínimo de vida digna será fijado a un determinado nivel y será el mismo para todos los trabajadores que participen en mercados privados o en mercados sociales de trabajo.

Como conclusión natural que deriva de las ideas expuestas, competerá al Estado, es decir, a la sociedad toda, asumir el costo financiero del trabajo en mercados sociales del mismo modo que asume, por ejemplo, el costo del servicio diplomático, de las Fuerzas Armadas, de la Policía, de la preservación ambiental, de la investigación científica en instituciones públicas, de la educación y salud pública, de las obras de saneamiento básico, etc. La gran diferencia radicará en que tanto la organización de los Mercados Sociales de Trabajo como las actividades de supervisión y control competerán a los Entes Regionales de Desarrollo y a las entidades sociales representativas de las propias comunidades. Al Gobierno Central, competerá, la gestión del financiamiento y la supervisión general a nivel nacional de la diversidad de Programas y Proyectos que podrán activar la Economía Social-Comunitaria en los ámbitos de las diferentes regiones del país.

La Tesis de las Tres Economías resulta del imperativo de una sociedad que, para asegurar su gobernabilidad, equidad y progreso, decide insertar en su aparato productivo la activa participación de toda la fuerza de trabajo disponible creando automáticamente soluciones eficientes a los problemas del desempleo, pobreza y exclusión social. Dentro de esta concepción, los mercados sociales de trabajo a ser organizados para absorber el desempleo existente utilizarán, como referencia, tanto los niveles salariales vigentes en el mercado laboral privado bien como los salarios mínimos de vida digna definidos desde fuera del ámbito de los mercados, en carácter de precios políticos establecidos deliberadamente por el Gobierno. No serán en consecuencia las expresiones de generosidad exterior o de sentimientos compasivos para aliviar los dramas sociales los que podrán resolver las carencias sociales. Tampoco deberían permanecer las prácticas del populismo inconsecuente que entrega dinero público a las familias pobres creando lazos de dependencia política partidaria sin ninguna exigencia de trabajo productivo por parte de la fuerza laboral en situación de desocupación.

ISSN:0212-8594 ISSN-e: 2340-2776. № DOI: http://dx.doi.org/10.12795/rea.2014.i31.05 
La Tesis de las Tres Economías sustenta que la creación, organización y funcionamiento de los mercados sociales de trabajo productivo serán actos deliberados del Gobierno, de la sociedad y de las comunidades locales para sumar energías sociales en beneficio directo de los más necesitados. Los antecedentes que orientan y sustentan tales percepciones provienen, esencialmente, de tiempos lejanos y reflejan la propia experiencia del hombre en sociedad.

En efecto, la historia ofrece ejemplos extraordinarios sobre la inteligencia de los gobernantes del pasado para organizar la fuerza de trabajo excedente transformándola en trabajos productivos que hicieron posible asegurar la supervivencia de sus poblaciones y crear fuentes permanentes de ingresos para el sustento financiero de sus países a largo plazo. La grandiosidad y belleza de las obras creadas con la participación de grandes artistas sobre la base del trabajo humano en gran escala no solo posibilitaron, en su tiempo, aliviar los problemas de la pobreza y del desempleo; posibilitaron organizar y administrar sustentos mínimos alimentarios para cientos de miles de personas y construir obras y monumentos que el tiempo transformó en valiosas expresiones culturales de la humanidad que los actuales gobernantes administran con extremo cuidado por configurar fuentes perennes de turismo internacional con inapreciable valor monetario: las pirámides de Egipto, las pirámides aztecas y mayas, las catedrales en ciudades de Europa, los caminos y canales de irrigación construidos por los Incas, las esculturas sobre rocas y montañas en diversos países del mundo y finalmente, la construcción del gran canal de $1.800 \mathrm{Km}$. entre las ciudades de Hangzhou y Beijing, la Gran Muralla, las montañas labradas con cientos de imágenes reproduciendo la figura de Buda y los ejércitos de terracota en la ciudad de Sian, todas las cuales fueron creaciones culturales consumadas por los emperadores y pueblos de China a lo largo de toda su historia milenaria.

\section{REQUISITOS PARA IMPLEMENTAR UNA ECONOMÍA SOCIAL-COMUNITARIA.}

Para dinamizar el empleo y la producción de bienes y servicios priorizando las necesidades sociales, se precisa desactivar diversas lógicas dominantes tanto en la praxis de gestión de los gobiernos como también en el funcionamiento tradicional de los mercados privados bajo el capitalismo.

\subsection{CAMBIOS EN LAS POLÍTICAS PÚBLICAS.}

La Tesis de las Tres Economías invierte radicalmente la lógica que orienta las Políticas de ajuste que practican los gobiernos bajo el entusiasta patrocinio de Entidades patronales y Organismos Internacionales y sustenta enfáticamente que los procesos de

ISSN:0212-8594 ISSN-e: 2340-2776. № DOI: http://dx.doi.org/10.12795/rea.2014.i31.05 
ajuste en la macroeconomía de los países no deberían implementarse reduciendo aún más los niveles de ocupación e ingresos percibidos por los sectores sociales dependientes del Trabajo ni tampoco amplificando la presión tributaria sobre las empresas que tradicionalmente fueron las mayores responsables por la creación de empleos en el país. Al contrario, la consistencia macroeconómica, la estabilidad social, el crecimiento, la seguridad y la gobernabilidad del futuro exigirá eliminar, en muy pocos años, la pobreza, el trabajo en negro, el desempleo y las carencias sociales elementales.

Esta nueva visión permitirá implementar nuevas políticas públicas para transformar las energías hoy desperdiciadas por millones de trabajadores desempleados y subempleados en energías creativas volcadas rigurosamente a incrementar la riqueza nacional mediante el Trabajo Productivo, el Trabajo para el Desarrollo Social y el Trabajo para la construcción de la Infraestructura Física Productiva que el país requiere en todas sus regiones.

Para que las ideas referidas no permanezcan en el limbo de las fantasías, será preciso impulsar la reorganización de la Economía y proceder a la creación de fuentes de trabajo en mercados privados y sociales para reinsertar a todos los desempleados. Adicionalmente, será preciso inducir el retorno de capitales y de buena parte de la inteligencia radicada en el exterior. En este marco, la incorporación de capitales y empresas extranjeras, serán expresiones ventajosas de modernización y cooperación internacional altamente bienvenidas pues contribuirán a la pronta recuperación y engrandecimiento de las economías nacionales.

Eliminada la posibilidad de utilizar las canteras del Trabajo y los ingresos de los trabajadores como espacios para desplegar las Políticas de Ajuste, se propone, como enfoque alternativo, consensuar los acuerdos políticos necesarios para implementar, simultáneamente, las radicales transformaciones y ajustes que requiere la economía en aspectos específicos de su política socio-laboral, en los programas del propio Gobierno a fin de reducir significativamente el Gasto Público y en las Políticas Tributarias, simplificando su administración, eliminando sus altos niveles de evasión, insertando en la legislación mecanismos de incentivos fiscales para expandir en el sector privado las inversiones reproductivas y extendiendo los impuestos sobre actividades no grabadas. Tales decisiones posibilitarán eliminar de la praxis gubernamental todo propósito de utilizar el Gasto Público como mecanismo de cooptación para asegurarse adhesión política en los sectores medios y pobres de la

ISSN:0212-8594 ISSN-e: 2340-2776. № DOI: http://dx.doi.org/10.12795/rea.2014.i31.05 REA 31 (2014): 98-126

http://www.publius.us.es/estudios_andaluces 
sociedad mediante una amplia gama de programas de subsidios y asistencialismo social sin ninguna contraprestación en términos de trabajo.

Las decisiones referidas permitirán reducir la excesiva presión fiscal que actualmente ejerce el Gobierno sobre familias y empresas privadas. La eliminación radical de la corrupción, la racionalización y descentralización del sector público y el pleno funcionamiento de la Justicia, penalizando realmente a quienes cometan delitos, serán poderosos instrumentos para recuperar la confianza en el progreso del país, inducir el retorno de los capitales, multiplicar las inversiones, amplificar la base de recursos públicos y la eficacia de las políticas públicas.

Las ideas expuestas sugieren la conformación de un nuevo Estado: más pequeño, eficaz, eficiente, espartano y descentralizado, demandante de menores recursos fiscales para el cumplimiento pleno de sus funciones. Para lograr tales resultados, las reformas en el Sector Público tendrán que realizarse de forma simultánea con la adopción de nuevos mecanismos institucionales que posibiliten una mayor participación ciudadana en la vida institucional del país a fin de asegurar el control social de las instituciones en defensa de sus propios intereses. Por su parte, las reformas necesarias de introducir en el mercado laboral para asegurar su mayor flexibilidad y productividad, podrán procesarse concomitantemente con la adopción de nuevas modalidades de reorganización empresarial destinadas a perfeccionar los mecanismos de participación del trabajo en la integración del capital y/o en la distribución de utilidades.

Por último, en un escenario alternativo de Ajuste Económico, la renegociación de la Deuda Pública, interna y externa, podrá también adoptar nuevas modalidades de renegociación, elevando al Honorable Congreso Nacional la responsabilidad de sancionar legislación específica autorizando al Poder Ejecutivo a reconocer y asumir el compromiso de pago de toda la Deuda Pública reconocida en carácter de Deuda Legítima bien como a renegociar, junto a acreedores públicos y privados, plazos y tasas variables de interés de forma compatible con la real capacidad de pago del país.

\subsection{CAMBIOS EN LA PRAXIS DE FUNCIONAMIENTO DE LOS MERCADOS PRIVADOS.}

Para el buen funcionamiento de una Economía Social-Comunitaria será necesario, además, erradicar de los mercados aquella lógica que a priori elimina toda demanda social que carece de capacidad monetaria. De igual modo, será preciso eliminar también la práctica bancaria que tan solo aprueba créditos para financiar proyectos de

ISSN:0212-8594 ISSN-e: 2340-2776. № DOI: http://dx.doi.org/10.12795/rea.2014.i31.05 REA 31 (2014): 98-126

http://www.publius.us.es/estudios_andaluces 
producción a aquellos pequeños empresarios que aseguren rentabilidad suficiente para cubrir el costo de la tasa de interés y una tasa razonable de ganancia.

Respecto a las lógicas a desactivar en los mercados conviene señalar que el capitalismo de libre mercado no construye riqueza en contextos donde predomina una potente demanda social sin capacidad monetaria aunque la realidad pueda ser expresiva en demostrar la vigencia de una relativa abundancia de recursos productivos subutilizados junto a una dotación de mano de obra desocupada o subocupada. Sobre aquella otra práctica que condiciona la concesión de créditos a la previa disponibilidad de rentabilidad suficiente para cubrir la tasa de interés y la tasa de ganancia, vale destacar la práctica adoptada por algunos gobiernos que para asegurar la inclusión de los pequeños empresarios en los créditos concedidos por los Bancos privados deciden cubrir, total o parcialmente, con recursos públicos, el costo de la tasa de interés prevista en los proyectos específicos.

En regiones dotadas de elevado potencial productivo pero con poblaciones sometidas a severas carencias sociales, desempleo y pobreza, será preciso instituir una nueva legislación laboral y social, más inclusiva y flexible que asuma, como prioridad absoluta, la necesidad de recuperar la dignidad de las personas asegurando trabajo productivo valorado por la sociedad o por el mercado. Esta es la razón esencial de una economía social comunitaria y el tiempo de su vigencia será función de las circunstancias concretas y específicas dominantes en cada país.

En casos extremos, donde imperen severas limitaciones naturales para ampliar la mediante la incorporación de mano de obra desocupada, competerá al Gobierno evaluar alternativas de colonización para desplazar poblaciones excedentes desde localidades inviables hacia otras geografías con potencialidades de producción para garantizar empleos productivos bajo condiciones de vida digna. Lo hizo Brasil en la década de los 60 transfiriendo excedentes de mano de obra (miles de familias) desde el nordeste semiárido hacia regiones preamazónicas situadas en los Estados de Marañao y Pará.

Al adoptar en una economía social-comunitaria una nueva lógica de interacción entre oferentes y demandantes de trabajo, los mercados podrán amplificar su oferta a corto plazo con la producción de bienes y servicios resultantes de proyectos de producción financiados con crédito público y recursos privados. En el propio proceso de expansión de la oferta se generarán los empleos y rentas que podrán absorber la fuerza de trabajo excedente potenciando la capacidad de compra de los trabajadores y familias que ingresan al mercado.

ISSN:0212-8594 ISSN-e: 2340-2776. № DOI: http://dx.doi.org/10.12795/rea.2014.i31.05 
En razón de los ingresos adicionales generados por la creación de trabajo productivo en los mercados privados y sociales, se amplificará mecánicamente la demanda de las familias pobres por bienes y servicios esenciales. En economías reguladas, los temores de inflación por haber utilizado ex - antes crédito público subsidiado o directamente la emisión monetaria como fuente de financiamiento para financiar la producción, el consumo y el empleo carecen de real justificación pues la afluencia de oferta real como resultado de la producción de ciclo corto llegará a los mercados de consumo en tiempos relativamente breves, inferiores al año, sin afectar en consecuencia los niveles de precios.

En su libro "Más dinero, más capital y más trabajo" el economista Hjalmar Schacht que administró la economía alemana en la década de los 30 decía:"si observamos el desarrollo normal del camino histórico, podremos apreciar que el va del trabajo, al capital y al dinero. ..... De igual manera como llegamos del trabajo al capital y al dinero, podemos llegar con el aporte del dinero a la obtención de capital y de trabajo." Concluía afirmando: "Un aumento de la circulación monetaria, simultáneamente con el aumento de la circulación de bienes, de ningún modo ocasiona fenómenos inflatorios". "Por este motivo, el Reichsbank dejó a un lado la teoría tradicional y puso en movimiento a la producción, proveyéndola de dinero nuevo, mediante una generosa aplicación del crédito. El éxito lo ha justificado. No reprodujo ningún efecto inflatorio, porque el volumen de bienes creció rápidamente en forma tal que ofreció un equivalente al incremento del volumen monetario."

En tiempos de globalización, ¿cuál podría ser la inserción internacional de una economía social-comunitaria? Si bien es cierto que las grandes corporaciones multinacionales controlan gran parte de los mercados de bienes y servicios a escala mundial, también es cierto que no llegan ni pueden controlar todos los flujos comerciales que simultáneamente acontecen en todas las regiones del mundo. El control de los mercados a escala global por parte de las grandes empresas multinacionales siempre ha sido parcial y selectivo y comprende tan solo aquellos bienes y servicios con mayor valoración económica quedando margen para la inteligente participación de empresas pequeñas o medianas de origen nacional en una amplia gama de otros mercados de bienes y servicios. En efecto, las grandes empresas trasnacionales articulan y unifican los mercados globales hilvanando en sus operaciones las islas de altos ingresos existentes en los diversos mercados y ciudades del mundo.

ISSN:0212-8594 ISSN-e: 2340-2776. № DOI: http://dx.doi.org/10.12795/rea.2014.i31.05 
Sin embargo, el resto de los mercados de servicios y bienes de consumo, que representan la mayor porción del PBI mundial, son de alcance nacional, regional, microregional o local. Su producción logra también comercializarse a escala internacional y existe una férrea competencia en razón de escalas de producción, condiciones de precios-calidad y de las particularidades técnicas que los productos contienen. En este tipo de mercados participan las pequeñas, medianas y grandes empresas nacionales y básicamente se concentran en bienes de consumo e intermedios.

La economía social comunitaria, motorizada por la fuerza de la pequeña empresa privada, cooperativa o comunitaria, puede actuar y competir con eficiencia en todos los tipos de mercados nacionales, regionales y locales aunque hasta el presente concentra su mayor participación en la producción de bienes y servicios de consumo. De forma asociada, lleva sus productos a los mercados mundiales de consumo agregando valor en función de sus particulares propiedades inherentes a su posición geográfica, pequeña escala de producción, reconocida calidad y exclusividad o al valor artístico o artesanal que imprime a su producción. Tales propiedades no surgieron espontáneamente. Fueron el resultado de extensos y persistentes esfuerzos tecnológicos, organizativos y de capacitación para asegurar que las producciones locales atiendan las exigencias de calidad y sanidad que requieren los mercados internacionales.

A pesar de las extremas diferencias existentes entre tipos y tamaños de empresas, la experiencia registra que las empresas transnacionales, las empresas nacionales y los emprendimientos inherentes a una economía social-comunitaria podrán coexistir en una misma región o país atendiendo fajas especializadas de los mercados y no necesariamente serán competidoras entre sí. Para lograr tal objetivo se requerirá, naturalmente, el apoyo inteligente de las Políticas Públicas y precisas normas de regulación y control. La experiencia del Almacén de barrio y el Supermercado integrante de alguna cadena multinacional es un ejemplo frecuente.

Si bien es cierto que en la economía real el comercio internacional está en manos de grandes empresas multinacionales que abastecen los grandes mercados, también es verdad que las pequeñas y medianas empresas de países subdesarrollados pueden participar con éxito económico en mercados globales siempre y cuando logren consolidar inteligentes procesos de organización asociativa para ampliar su escala operacional en las etapas del mercado internacional. A este respecto, destacan, como ejemplos, experiencias exitosas realizadas por pequeñas empresas artesanales-

ISSN:0212-8594 ISSN-e: 2340-2776. № DOI: http://dx.doi.org/10.12795/rea.2014.i31.05 
industriales de carácter familiar situadas en regiones del norte de Italia; en pueblos de los Pirineos en España, en las cooperativas de pequeños agricultores de Costa Rica, en las artesanías de Ecuador o en pueblos rurales del sur de la provincia de Santa Fe, Argentina, donde se asentaron las pequeñas fábricas especializadas en la producción para mercado interno y externo de maquinarias para la producción y cosecha agropecuaria. La fábrica de grandes máquinas que en la actualidad perforan en diversos países del mundo túneles, caminos y pozos bajo tierra o atraviesan montañas, nació como pequeña empresa familiar en un pequeño pueblo de Alemania.

\section{APORTES CONCEPTUALES QUE CONTIENE LA TESIS DE LAS TRES ECONOMÍAS.}

Desde el siglo XVIII, el pensamiento clásico asociaba la naturaleza y causa de la riqueza de las naciones a la existencia de un hombre libre, a un Estado con roles subsidiarios, al funcionamiento de mercados transparentes y competitivos y a un libre comercio internacional. Las ideas expuestas amarradas en la dinámica del binomio EstadoMercados sustentaron las bases del liberalismo económico y del propio sistema capitalista.

Tras 200 años de expansión del capitalismo, la brutal crisis económica y social que la década de los 30 detonó en los países centrales, amenazó la sustentabilidad del propio sistema. En aquel contexto, el pensamiento de Keynes articuló nuevas visiones propositivas para estabilizar los ciclos económicos y asegurar el mejor funcionamiento del binomio Estado-Mercado. En su obra mayor Keynes, J.M. (1997) concluía que para estabilizar las tendencias al crónico desequilibrio de la economía y avanzar hacia el progreso económico, será necesario accionar roles activos del Estado en el manejo de la moneda, del crédito, de la inversión y el gasto público.

Hacia la década de los 50, desde la CEPAL, Raúl Prebisch enseñaba a entender la Economía del Desarrollo y la Política Económica dentro de una totalidad en que los países de la Periferia, para contrarrestar los impactos económicos y sociales derivados de la inestabilidad crónica de los Centros, debían adoptar políticas activas y diferenciadas para realizar reformas estructurales y avanzar deliberadamente hacia la planificación, la industrialización y la integración de sus economías.

Las ideas de Prebisch, sentando las bases de una escuela Cepalina de pensamiento más apropiada para comprender la dinámica de las economías latinoamericanas, deslegitimaron las proposiciones emanadas desde la ortodoxia y aportaron originalidad al pensamiento económico. Vale destacar, sin embargo, que las Políticas Públicas resultantes de aquel pensamiento siempre se proyectaron desde dentro de

ISSN:0212-8594 ISSN-e: 2340-2776. № DOI: http://dx.doi.org/10.12795/rea.2014.i31.05 
un escenario bidimensional Estado-Mercado señalando, al igual que Keynes, la necesidad de ampliar la participación de los gobiernos en la resolución de los problemas económicos y sociales.

Hacia el mismo tiempo, el pensamiento europeo de postguerra daba formas a una nueva escuela en política económica trazando puentes programáticos entre socialismo y capitalismo para avanzar hacia la convergencia de sistemas sociales. Gunnar Myrdal y Jan Tinberger fueron sus mayores exponentes y sus ideas sustentaron el posterior desarrollo de los estados de bienestar que expandieron su influencia en la institucionalidad de los países de Europa Central.

Dejando de lado las ideas de organización social emanadas del socialismo, los parágrafos precedentes, expresaron, de forma sintética, hitos mayores en la evolución histórica del pensamiento económico. Las diversas escuelas referidas, aunque presentaron medulares diferenciaciones entre sí, surgieron de una misma matriz conceptual que situaba el destino de las sociedades en el marco de las acciones dominantes o subsidiarias del Estado y/o del Mercado.

La Tesis de las Tres Economías, elaborada en sintonía con las nuevas inquietudes sociales que recorren el mundo, pretende aportar un nuevo eslabón en la trayectoria de las ideas. Sustenta, en efecto, que en tiempos de acentuada concentración y globalización comercial, financiera y tecnológica, aquel binomio tradicional de Estados y Mercados ya es insuficiente para producir, en el seno de las economías dependientes, condiciones de progreso y equidad.

Los indicadores relativos a la distribución de ingresos entre estratos sociales, junto a aquellos que dimensionan el desempleo real, la pobreza y la indigencia, la desnutrición y la precariedad de las políticas de educación, vivienda, salud y seguridad no pueden ser manipulados a voluntad por los gobiernos $y$, tarde o temprano, revelan las severas inequidades sociales que sigue caracterizando a los procesos de desarrollo en diversas regiones del mundo.

Esta estructural inviabilidad no solo se verifica en el ámbito de los países latinoamericanos. El gradual debilitamiento de los estados de bienestar en Europa y la ampliación de las diferenciaciones sociales dentro de la economía americana son expresiones concretas de un nuevo fenómeno que articula el progreso económico y tecnológico con menores requerimientos de trabajo ampliando la inexorable ocurrencia de procesos irreversibles de exclusión social.

ISSN:0212-8594 ISSN-e: 2340-2776. № DOI: http://dx.doi.org/10.12795/rea.2014.i31.05

REA 31 (2014): 98-126

http://www.publius.us.es/estudios_andaluces 
La Tesis de las Tres economías sustenta, como epicentro de sus convicciones, que para que las sociedades pobres puedan desencadenar procesos inclusivos de desarrollo será preciso incorporar, orgánicamente, en el juego de las relaciones sociales e institucionales, la activa participación de las comunidades locales, de los desempleados y subempleados, de las pequeñas empresas y perdedores del sistema, como un tercer protagonista necesario para emprender la construcción de un futuro mejor.

En el monumento levantado en Washington en homenaje a Teodoro Roosevelt - uno de los más grandes Presidentes en la historia de los Estados Unidos - se grabó en la piedra algunas de sus frases más célebres y demostrativas de la fuerza de sus convicciones para enfrentar la Gran Depresión y transformar el país. Decía: The test of our progress is not whether we add more to the abundance of those who have much. It is whether we provide enough for those who have too little. No country, however rich, can afford the waste of its human resources. Demoralization caused by vast unemployment is our greatest extravagance. Morally, it is the greatest menace to our social order.

\section{VERTIENTES IDEOLÓGICAS QUE SUSTENTAN LA TESIS.}

\subsection{LA INFLUENCIA DEL PENSAMIENTO SOCIAL EUROPEO Y ANGLOAMERICANO.}

En la larga lista de intelectuales que aportaron sus ideas para enriquecer las bases de una ideología de cambio, vale destacar los aportes teóricos realizados por Jean Louis Laville (2004), André Gortz (1998), Roger Godino (1999), E.F. Schumacher (1973) y Jeremy Rifkin (2000) para construir una sociedad más justa, mejorando las condiciones de empleo y renta de las comunidades y elevando sus niveles de autonomías locales.

Al referir el marco conceptual de la economía solidaria, Laville (2004) señala con precisión los límites de la economía de mercado y al respecto dice que en razón de sus resultados concretos, no podrá constituirse en tránsito hacia una sociedad de mercado. En esta simple observación, se concentran las razones que fundamentan los esfuerzos que diversas regiones del mundo vienen realizando para instituir nuevas formas de economía plural donde el afán mercantil, la reciprocidad entre personas y organizaciones y la redistribución desde las instituciones de gobierno posibiliten crear condiciones para el progreso económico bajo normas de libertad y equidad que puedan merecer el consenso social.

ISSN:0212-8594 ISSN-e: 2340-2776. № DOI: http://dx.doi.org/10.12795/rea.2014.i31.05 


\section{-El pensamiento social de André Gortz.}

Toda su producción intelectual se concentra en pensar el futuro de la humanidad a partir del hecho concreto de que han concluido los tiempos de la sociedad de trabajo y se avecinan los tiempos de una nueva sociedad de cultura. En su libro "Miserias del presente, riqueza de lo posible", Gortz (1998) señala: "que cada día se produce más con un volumen decreciente de capital y trabajo. En consecuencia, la producción distribuye a un número decreciente de activos un volumen decreciente de remuneraciones y de salarios. Disminuye el poder de compra de una proporción creciente de la población. El desempleo, la pobreza la miseria absoluta se expande. La productividad rápidamente creciente del trabajo y del capital entraña un excedente de fuerza de trabajo y de capital. Este busca agrandarse sin pasar por la intermediación del trabajo productivo - operaciones en los mercados financieros y de cambios - o invirtiendo en países de salarios muy bajos. Las actividades e inversiones no rentables a corto plazo, dejan de ser financiables en parte por la caída de los salarios y en parte por las exoneraciones fiscales que los estados consienten al capital para frenar su éxodo."

La pregunta esencial que se plantean quienes analizan la necesidad de asegurar un ingreso social es quien y como financiarlo. Los estados no tienen condiciones de solventar este gasto. Para intentar una respuesta, André Gortz invoca reflexiones de algunos grandes maestros: "en sus escritos de 1857, Marx ya había predecido que "la distribución de los medios de pago deberá corresponder al volumen de riquezas socialmente producidas y no al volumen del trabajo ofrecido". Y cita también a Wassily Leontieff, premio nóbel de economía cuando dice: "cuando la creación de riquezas no depende más del trabajo de los hombres, estos morirán de hambre en las puertas del paraíso, a menos que se responda por medio de una nueva política de ingresos a la nueva situación técnica."

\section{-El pensamiento de Roger Godino.}

En su libro "Los siete Pilares de la Reforma" (1999), el autor señala que el progreso técnico es responsable por la ola de desempleo que sacude al planeta pero que, racionalmente, no puede ni debe ser condenado. Tampoco el comercio internacional, que facilita en los países la entrada de productos procedentes de regiones con bajos salarios. Ante tal situación, las salidas tendrán que buscarse en otras direcciones y señala, al respecto, una diversidad de alternativas que incluyen desde la reforma de las empresas hasta cambios en la legislación laboral y en las políticas tributarias. En este propósito, recomienda que los gobiernos, mediante políticas inteligentes, podrían reducir el costo del salario para estimular en los empresarios sus decisiones a contratar más trabajadores. No pudiendo rebajarse los actuales niveles salariales de bolsillo,

ISSN:0212-8594 ISSN-e: 2340-2776. № DOI: http://dx.doi.org/10.12795/rea.2014.i31.05 
propone bajar los costos asociados al salario $y$, en particular, aquellos asociados al sistema de salud. Enfatiza que la salud es cuestión de Estado y sus instituciones tendrán que asumir la total responsabilidad por instituir un sistema universal, común y obligatorio, a todos los ciudadanos.

\section{-El pensamiento de E.F. Schumacher}

Su libro "Lo pequeño es hermoso", publicado en 1973 en su edición original en inglés y en 1983 en español, ha sido considerado un clásico por la literatura destinada a reflexionar sobre cambios posibles dentro del sistema social del capitalismo. En esencia, sustenta la necesidad de replantear las bases de las políticas de desarrollo priorizando el beneficio directo de los más necesitados. Su libro es un himno al desarrollo local, en base a medianas y pequeños emprendimientos empresarios. En su prédica sustenta que la base de la cooperación para combatir la pobreza debería focalizarse en llevar al interior de las comunidades aportes concretos para mejorar la educación, la organización y la disciplina grupal para dar consecuencia a decisiones colectivas. Entre sus principales recomendaciones destacan aquellas de liberar de impuestos a las grandes empresas a cambio de ceder acciones por la mitad de sus ganancias.

El autor focaliza la principal contradicción que genera el régimen de gran propiedad dentro del sistema social dominante y concluye que en la medida en que el estado financia la inversión en infraestructura, tanto física como en recursos humanos para beneficio directo del gran sector privado empresarial, las empresas deberían abrir su capital accionario y reembolsar al estado por tales aportes. El método de que el estado invierte en infraestructura, educación, salud, etc y las empresas privatizan las ganancias pagando impuestos al gobierno no funciona ni es justo pues las empresas recurren a mil formas de burlar sus compromisos tributarios y terminan recibiendo mucho más de lo que realmente reintegran por medios tributarios.

\section{-El pensamiento de Jeremy Rifkin.}

Su pensamiento, reflejado básicamente en su libro Fin del Trabajo remeció, con la fuerza de un volcán, las conciencias del mundo y alertó sobre procesos inexorables que la sociedad contemporánea no ha sabido, no ha querido o no ha podido resolver y que, como consecuencia, tarde o temprano, ocasionarán el caótico derrumbe del orden social vigente. El mayor aporte de su pensamiento se concentra en sus proposiciones destinadas a instituir y perfeccionar en la vida de las sociedades organizadas, un tercer sector económico donde se puedan resolver los problemas sociales del desempleo y de

ISSN:0212-8594 ISSN-e: 2340-2776. № DOI: http://dx.doi.org/10.12795/rea.2014.i31.05 
la pobreza situados más allá de las soluciones que el mercado o los gobiernos puedan arbitrar.

"Si el talento, la energía y los recursos de cientos de millones de hombres y mujeres no se reconducen hacia objetivos constructivos, la civilización continuará, con toda probabilidad, su camino hacia la desintegración y la conformación de un estado de creciente violencia social y de carencia de ley, del que puede resultar muy difícil hacer el camino inverso. Por esta razón, encontrar una alternativa al trabajo formal en la economía de mercado resulta la tarea crítica de todas las naciones de la Tierra. La preparación para una era posterior a la de mercado requerirá una gran atención a la construcción del tercer sector y a la renovación de la vida comunitaria. A diferencia de la economía de mercado, que al basarse única y exclusivamente en el concepto de productividad posibilita la substitución de los seres humanos por las máquinas, la economía social se centra en las relaciones humanas, en los sentimientos de intimidad, en el compañerismo, en los lazos fraternales y en el sentido de responsabilidad social en la administración de los recursos, todas ellas cualidades no fácilmente reductibles o reemplazables por máquinas....."

\subsection{EL PENSAMIENTO DE LA IGLESIA CATÓLICA.}

Las realidades del mundo contemporáneo anticipan que la evolución del capitalismo real y financiero podrá avanzar durante el siglo XXI hacia la conformación de dos escenarios mundiales alternativos: el primero presume que el mundo avanzará hacia un capitalismo todavía más concentrado sustentado en ganancias revolucionarias de productividad como consecuencia de la aplicación por las grandes empresas multinacionales de los revolucionarios avances tecnológicos ya disponibles en el campo de las ciencias sin tomar en consideración las consecuencias sociales de un elevado desempleo y pobreza ni la pérdida gradual de soberanía por parte de los Estados Nacionales como consecuencia del avance continuo de las mega empresas internacionales en el amplio escenario del capitalismo global.

El segundo escenario proclama que bajo la hegemonía del capitalismo globalizado, el mundo podrá entronizar el progreso económico permanente incorporando no solo los avances tecnológicos de última generación sino también las energías de millones de seres humanos en condiciones de pobreza, desempleo y exclusión. Desde esta perspectiva, la demanda potencial para sustentar niveles más elevados de inversión dentro del capitalismo provendrá, necesariamente, de la inserción productiva y consecuente ampliación del consumo de los cientos de millones de habitantes que

ISSN:0212-8594 ISSN-e: 2340-2776. № DOI: http://dx.doi.org/10.12795/rea.2014.i31.05 
hasta el presente quedaron marginados o excluidos en los mercados de trabajo y consumo.

Para transformar en realidad esta utopía, será preciso que la propia comunidad mundial de naciones rediseñe los marcos institucionales y socio-políticos destinados a avanzar hacia sociedades menos antagónicas y socialmente más equitativas motivadas para reducir la brecha social a escala mundial y potenciar los valores espirituales defendidos tanto por el cristianismo original como por la revolución protestante que en el siglo XVI sentó las bases del capitalismo moderno.

Este segundo escenario, evidentemente, está preñada de idealismo y buenas intenciones. Presupone el imperativo de volver a los preceptos de Martín Lutero y Juan Calvino para reinsertar en la sociedad contemporánea los valores fundantes de la reforma protestante que dio sustento al capitalismo europeo a partir del siglo XVI. Quienes proponen tales destinos imaginan que avanzando por esta dirección el mundo del siglo XXI podrá valorizar nuevamente las virtudes de la palabra empeñada, de la honestidad de trato, del respeto entre las personas, de la ética del trabajo, de las virtudes de la riqueza y del ahorro, de la justicia, del rol de las instituciones y de la imperiosa necesidad de avanzar hacia un mundo más justo mediante la contención de la codicia, la profundización de prácticas de solidaridad mediante la voluntaria transferencia de ingresos de quienes más tienen hacia sectores carentes y la fijación de límites a las prácticas de un capitalismo financiero desmadrado.

En la última y reciente encíclica del Papa Benedicto XVI de junio 2009, en el punto 36, se lee lo siguiente: "La actividad económica no puede resolver todos los problemas sociales ampliando sin más la lógica mercantil. Debe estar ordenada a la consecución del bien común, que es responsabilidad sobre todo de la comunidad política. Por tanto, se debe tener presente que separar la gestión económica, a la que correspondería únicamente producir riqueza, de la acción política, que tendría el papel de conseguir la justicia mediante la redistribución, es causa de graves desequilibrios."

Al final del punto 37 dice que...." Para eso, es necesario que en el mercado se dé cabida a actividades económicas de sujetos que optan libremente por ejercer su gestión movidos por principios distintos al del mero beneficio, sin renunciar por ello a producir valor económico. Muchos planteamientos económicos provenientes de iniciativas religiosas y laicas demuestran que esto es realmente posible."

En el punto 38 de la referida encíclica dice que ".... mi predecesor Juan Pablo II señaló esta problemática al advertir la necesidad de un sistema basado en tres instancias: el

ISSN:0212-8594 ISSN-e: 2340-2776. № DOI: http://dx.doi.org/10.12795/rea.2014.i31.05 
mercado, el Estado y la sociedad civil. Consideró que la sociedad civil era el ámbito más apropiado para una economía de la gratuidad y de la fraternidad, sin negarla en los otros dos ámbitos. Hoy podemos decir que la vida económica debe ser comprendida como una realidad de múltiples dimensiones: en todas ellas, aunque en medida diferente y con modalidades especificas, debe haber respeto a la reciprocidad fraterna. En la época de la globalización, la actividad económica no puede prescindir de la gratuidad, que fomenta y extiende la solidaridad y la responsabilidad por la justicia y el bien común en sus diversas instancias y agentes. Se trata, en definitiva, de una forma concreta y profunda de democracia económica..."

En el mismo punto 38 de la encíclica Caritas in Veritate, el Papa Benedicto XVI dice.... "Junto a la empresa privada, orientada al beneficio, y los diferentes tipos de empresas públicas, deben poderse establecer y desenvolver aquellas organizaciones productivas que persiguen fines mutualistas y sociales. De su recíproca interacción en el mercado se puede esperar una especie de combinación entre los comportamientos de empresa, y con ella, una atención más sensible a una civilización de la economía. En este caso, caridad en la verdad significa la necesidad de dar forma y organización a las iniciativas económicas que, sin renunciar al beneficio, quieren ir más allá de la lógica del intercambio de cosas equivalentes y del lucro como fin en sí mismo."

Desde una perspectiva histórica, vale resaltar que si el capitalismo del siglo XXI pudiera avanzar en el marco de las ideas referidas, el mundo podrá llegar a restablecer y actualizar los principios básicos del "pietismo", movimiento moral y religioso destinado a perfeccionar la reforma luterana mediante la aplicación de su principio central: "en las cuestiones esenciales, unidad; en aquellas no esenciales, libertad; en todos los casos, caridad".

Los principios y prácticas del "pietismo", como movimiento religioso originado en la Alemania del siglo XVI, impulsaron en países centrales de Europa y, particularmente en Escandinavia, la configuración de sociedades más equitativas. Tales principios prevalecieron también en los orígenes de la formación espiritual de la sociedad norteamericana. En la práctica, el pietismo creó condiciones especiales de conciencia social que al situar sus fundamentos más allá de los preceptos religiosos del cristianismo, impulsó entre las familias ricas y pobres significativas transferencias de recursos que posibilitaron la gradual formación de sociedades más justas y solidarias.

Ante la imposibilidad de prever científicamente cual de las dos alternativas antes referidas podrá marcar las huellas del futuro, es de esperar, en el terreno intelectual de las predicciones, que el mundo, en una síntesis dialéctica superadora, logre

ISSN:0212-8594 ISSN-e: 2340-2776. № DOI: http://dx.doi.org/10.12795/rea.2014.i31.05 
encontrar, en un futuro no muy distante, un nuevo camino de estabilidad y progreso basado en la convergencia de los dos escenarios anteriormente referidos.

La masificación y globalización de la protesta social en los próximos años alumbrará los caminos de salida al crear las condiciones necesarias para institucionalizar, a escala global, el control y la regulación social de los instintos desmedidos de codicia del capitalismo global. De este modo, todo aquello que los movimientos de la Reforma en el siglo XVI impulsaban en el plano de las ideas y de las conciencias y no pudieron lograrlo para condicionar los límites morales del capitalismo emergente a fin de asegurar su viabilidad y permanencia, será posible concretarlo en el próximo futuro.

Ahora bien, para que el capitalismo pueda estabilizar su mecánica de funcionamiento mediante la propiedad privada, las empresas y la libertad de mercados, tendrá que asegurar, como condición de equidad, que los impuestos transferidos al estado sean suficientes para financiar el funcionamiento pleno de la Economía Social-Comunitaria, posibilitando la generación de los empleos necesarios en los mercados sociales y la provisión de los servicios esenciales para asegurar niveles de vida digna a todas las familias. ¿Qué mecanismo tendrá que funcionar en las sociedades para asegurar la funcionalidad del capitalismo y de los Gobiernos al progreso y bienestar de los pueblos?

Solo un Poder Social cristalizado podrá mantener, bajo control permanente, la conducta moral e inteligencia de gestión de sus Gobernantes y Elite Política Dirigente y esta condición solo podrá verificarse en el seno de las naciones mediante el tiempo, la educación, organización y conciencia crítica de las mayorías sociales.

La existencia de Poder Social tornará posible mediante los instrumentos de las democracias electorales que cuando los Gobiernos no logren concretar los avances que los pueblos reclaman, la sociedad retome su derecho inalienable para experimentar y regular nuevas formas de organización económica y social a fin de instituir relaciones sociales compatibles con el bienestar colectivo. En tiempos de intensa globalización, la permanencia del capitalismo como motor esencial para el progreso y bienestar social, exigirá, en consecuencia, concebir las formas de organización social y económica y los derechos de propiedad como instrumentos, como variables de ajuste. De igual modo, la cristalización del Poder Social permitirá asegurar que los Gobernantes, en la gestión de los Ingresos y Gasto Público, actuarán con eficacia y extrema moralidad eliminando de cuajo manifestaciones de corrupción. Habida cuenta de tales exigencias, desaparecerá en poco tiempo la práctica de utilizar

ISSN:0212-8594 ISSN-e: 2340-2776. № DOI: http://dx.doi.org/10.12795/rea.2014.i31.05 REA 31 (2014): 98-126

http://www.publius.us.es/estudios_andaluces 
el desempleo, la exclusión social y la pobreza como variables de ajuste para asegurar la estabilidad del propio sistema capitalista.

Con la adopción de la Tesis de las Tres Economías los pueblos podrán cristalizar su Poder Social destinado a legitimar y controlar al Poder Formal (Ejecutivo, Legislativo y Judicial). El Poder Real, interno y externo, gradualmente, tras reconocer al Poder Social soberanía y potestad por representar el Único Poder verdadero y permanente, será inducido a flexibilizar sus conductas para consensuar niveles razonables de apropiación relativa de la Renta entre los diversos sectores sociales y ampliar las perspectivas de un mejor futuro para las próximas generaciones. Ya son varios los países que en el mundo avanzan impulsados por nuevas formas de Capitalismo en procura del progreso y bienestar de las sociedades transformando la moral pública, la dignidad de todas las personas y la preservación ambiental que impone el siglo XXI en poderosos condicionantes de sus Políticas Públicas.

\section{CONCLUSIONES.}

Desde el momento en que los países permanecen bajo modelos de fuerte inequidad en la distribución del ingreso, con elevado desempleo, pobreza y exclusión social, no podrán evitarse manifestaciones sociales de inestabilidad, violencia e ingobernabilidad. En tales contextos, los sectores sociales de altos ingresos y el complejo de grandes empresas enfrentarán crecientes dificultades para mantener sus actividades productivas y conservar siquiera su histórica participación en la riqueza y en la renta nacional.

La historia registra que a partir del momento en que una sociedad reduce la vitalidad de su mercado de trabajo y petrifica severos niveles de inequidad, su gobernabilidad quedará comprometida. La inseguridad y violencia social podrá apropiarse del destino de la Nación consumiendo, gradualmente, las riquezas de los sectores sociales que las poseen para asegurar, de alguna manera, la miserable supervivencia de aquellos sectores sociales sometidos a situaciones extremas de precariedad social. En tales contextos, ninguna Política Macroeconómica sustentada tan solo en el pulcro funcionamiento del binomio Estado-Mercado podrá resultar exitosa. Como enfatizado en la Tesis de las Tres Economías, el mundo cambió y ha llegado el momento de emprender nueva políticas macroeconómicas con Ajustes no Ortodoxos y comprender que para acrecentar la riqueza de las naciones será preciso incorporar, además del Estado y el Mercado, la activa participación de los "perdedores del sistema" poniendo en funcionamiento los Mercados Sociales de Trabajo en el marco de una nueva Economía Social-Comunitaria.

ISSN:0212-8594 ISSN-e: 2340-2776. № DOI: http://dx.doi.org/10.12795/rea.2014.i31.05 
Por virtud del avance tecno-científico y de las nuevas tecnologías de comunicación a escala mundial, gran parte de la población mundial que no encuentra trabajo digno y sobrevive con severas dificultades se informa diariamente sobre los patrones internacionales de consumo y altos niveles de bienestar que predominan en ciertos países y sectores de altos ingresos. La diaria exposición de tamañas diferenciaciones culturales determina, a escala mundial, la espontánea expansión de las aspiraciones colectivas por materializar mejores niveles de vida y cuando los mercados del mundo demuestran su creciente incapacidad para generar los empleos y la masa de ingresos monetarios que los pueblos necesitan para cubrir sus necesidades vitales desencadenan, necesariamente, incontenidos torrentes de reclamos sociales. No existe mecanismo político, policial ni militar alguno capaz de impedir y paralizar el despertar de las aspiraciones colectivas. Solo la Alta Política podrá concebir y aplicar reformas en los sistemas económicos que posibiliten avanzar soluciones a este problema que asume escala universal.

En la etapa actual de intensa globalización del capitalismo ha llegado el momento en que la clase dirigente a escala mundial reconozca y asuma esta lección de la realidad y de la historia. De igual modo, también ha llegado el momento para que las Universidades y Academias de Ciencias Sociales asuman también el compromiso de abrir sus mentes, superar sus artificiales diferenciaciones disciplinarias y avanzar en el necesario debate teórico para unificar la comprensión de este trágico hecho cultural de alcance universal abriendo nuevos caminos para la construcción de alternativas de reformas en el seno del Capitalismo Globalizado que por el momento rige los destinos del mundo en carácter hegemónico. La Tesis de las Tres Economías fue escrita como una contribución a este impostergable debate.

\section{BIBLIOGRAFÍA}

Benedicto XVI (2009): Encíclica La caridad en la verdad.

Bergoglio, J. (2013): La nación por construir. Editorial Claretina, Buenos Aires.

Brahm, L.J. (2002): China after WTO. Compiled and edited by Laurence J., Published by China Intercontinental Pres.

Dosman, E. (2010): La vida y la época de Raúl Prebisch. Universidad de Alcalá, Ediciones Jurídicas y Sociales, Madrid

Dupuy, J.P. (1998): El sacrificio y la envidia. Gedisa, Barcelona.

Figueroa, M. (2003): El Desafío Argentino, un modelo autónomo de desarrollo. Buenos Aires, editorial Aplicación Tributaria., página 43/44

ISSN:0212-8594 ISSN-e: 2340-2776. № DOI: http://dx.doi.org/10.12795/rea.2014.i31.05

REA 31 (2014): 98-126

http://www.publius.us.es/estudios_andaluces 
Figueroa, M. (2004): Argentina Entrampada. Editorial Piso - 12, Buenos Aires.

Godino, R. (1999): Los siete Pilares de la reforma. Ediciones Dolmen, Chile.

Gortz, A. (1998): Miserias del presente, riqueza de lo posible. Pág. 89/120. Paidós, Buenos Aires.

Keynes, J.M. (1997): Teoría general de la ocupación, el interés y el dinero. 1936. FCE.

Laville, J.L. (2004): Economía Social y Solidaria. Editorial Altamira. Buenos Aires.

Lietaer, B. (2006): El futuro del dinero. Editorial Longseller, Bs.As.

Rifkin, J. (2000): El fin del trabajo, Paidós, Bs. As.

Schumacher, E.F. (2001): Lo pequeño es hermoso. Ediciones AKAL.

Smith, A. (1776): Investigación sobre la naturaleza y causas de la riqueza de las naciones. 